\title{
Supersensitivity and gastric emptying after vagotomy
}

J. TINKER, N. KOCAK, T. JONES, H. I. GLASS, AND ALAN G. COX ${ }^{1}$ From the Departments of Surgery, Medical Physics, and the MRC Cyclotron Unit, Royal Postgraduate Medical School, Hammersmith Hospital, London W12

SUMMARY Investigations were carried out in man and dog to study the validity of Cannon's law of denervation supersensitivity in relation to parasympathetic denervation of the stomach. Subthreshold doses of carbachol did not accelerate gastric emptying before vagotomy but caused a significant increase in the rate of gastric emptying after vagotomy. These findings may be relevant to aberrations of gastrointestinal motility after vagotomy and may provide the basis of a test for completeness of gastric vagotomy.

Changes in alimentary motility after vagotomy, such as diarrhoea, remain unexplained. One possibility is that they may be related to hypersensitivity of denervated muscle of the alimentary tract, and we now report a study designed to investigate this phenomenon after vagotomy.

In 1939 Cannon proposed his 'law of denervation supersensitivity'. This states that a denervated organ responds to chemical agents in doses too small to stimulate the normally innervated organ; such doses are called 'subthreshold'. Cannon's law was framed largely in terms of sympathetic and somatic denervation. In order to determine whether Cannon's law is valid for parasympathetic denervation, we decided to measure the effect of subthreshold doses of a cholinergic drug (carbachol) on the rate of gastric emptying before and after vagotomy.

\section{Methods and Material}

Three adult greyhound bitches were studied first and the validity of Cannon's law in relation to gastric emptying was verified. We therefore instituted a comparable investigation in man. The patients were five volunteers from our gastric clinic in whom a vagotomy and pyloroplasty for

Received for publication 2 December 1969.

${ }^{1}$ Present address: Division of Surgery, Northwich Park Hospital, and Clinical Research Centre, Harrow, Middlesex. duodenal ulcer had been carried out two to four weeks previously. The vagotomy was complete in all, as judged by the result of the insulin test (Hollander, 1946). Five patients admitted for minor surgery volunteered to serve as controls.

METHOD OF STUDY

In both dog and man the rate of gastric emptying was measured by external counting of a radioisotopically labelled meal. The methods used were different.

\section{Method in dogs}

The rate of gastric emptying was measured in each dog before and after complete truncal vagotomy and pyloroplasty.

This method was developed by $\mathrm{Mr} \mathrm{H}$. Daintree Johnson (personal communication, 1969). After an overnight fast, each dog was supported in a Pavlov stand. The small intestine was shielded with a lead plate leaving only the profile of the stomach, previously determined by a barium meal, exposed to a counter fixed $24 \mathrm{~cm}$ from the dog. Saline or carbachol was injected intravenously and immediately thereafter a standard meal in a bowl was fed to the dog. The meal consisted of $250 \mathrm{ml}$ of water to which was added $1.8 \mathrm{~g} \mathrm{NaCl}$ to make the meal isotonic, $30 \mathrm{ml}$ Protogest (a mixture of amino acids) to make it palatable, and $10 \mu \mathrm{Ci}$ of radioactive colloidal gold $\left({ }^{198} \mathrm{Au}\right.$ which has a half-life of 2.7 days). 


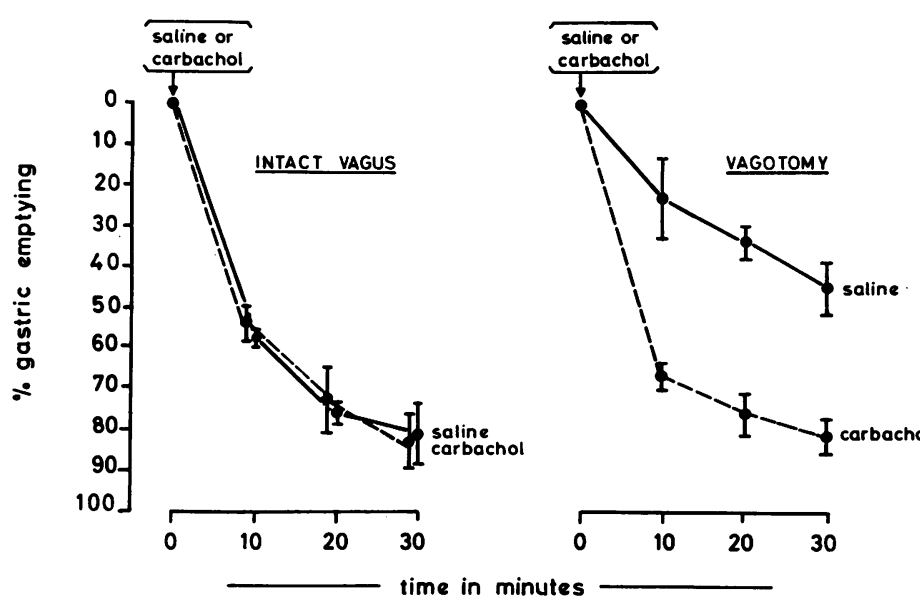

Fig. 1 The effect of subthreshold carbachol on the rate of gastric emptying in the dog before and after complete truncal vagotomy.

As soon as the dog had finished the meal, oneminute counts were taken every two minutes for 36 minutes, giving 19 measurements for each experiment.

Before vagotomy and pyloroplasty each dog had 18 gastric emptying studies: three after an intravenous injection of $1.0 \mathrm{ml}$ saline (control studies) and three each after intravenous injection of $0.06,0.125,0.25,0.5$, and 1.0 micrograms of carbachol per kilogram body weight.

On completion of these experiments a transthoracic truncal vagotomy and a HeinekeMichulicz pyloroplasty were carried out. In each dog the vagotomy was judged to be complete on the basis of an insulin test. Three weeks later the gastric-emptying studies were repeated after an injection of either saline or carbachol. The effects of only three doses of carbachol were investigated $(0.06,0.125$, and 0.25 micrograms per kilogram body weight).

\section{Method in patients}

The rate of gastric emptying of a test meal was measured using a gamma camera by a method described in a separate communication (Jones et al, in press). The test meal consisted of $300 \mathrm{ml}$ milk, two slices of lightly buttered white bread, three teaspoons of jam, and two scrambled eggs. One hundred $\mu \mathrm{Ci}$ of ${ }^{129} \mathrm{Caesium}$, absorbed onto zirconium phosphate to prevent absorption, was mixed with the milk and eggs. Carbachol in a dose of 0.06 micrograms per kilogram body weight or an equivalent volume of saline was injected immediately before ingestion of the test meal which took a further 15 minutes to eat. Gastric emptying was measured once each with carbachol and saline in each patient.

After completion of the test meal the patient lay supine under a gamma camera for the remainder of the investigation. The camera was used to demonstrate the profile of the stomach, and the first count of its radioactive contents was made 25 minutes after the patient started to eat the meal. Further counts were made for 100 seconds at intervals of two minutes for 65 minutes. In each volunteer two measurements of gastric emptying were taken: the first after injection of saline and the second after injection of the subthreshold dose of carbachol.

\section{ANALYSIS OF RESULTS}

In both dogs and patients, the initial count was taken to represent the amount of radioactivity in the stomach before it emptied and subsequent counts were calculated as a percentage of this initial count. The average interval between starting to eat the test meal and the initial count was 2 minutes in the dog and 25 minutes in man. The mean percentage gastric emptying was calculated in the dog 10, 20, and 30 minutes after the initial count and in man $5,15,25,35,45,55$, and 65 minutes after the initial count.

Student's $t$ test was used to calculate the significance of differences between means. Differences with a $P$ value of less than $5 \%$ were regarded as statistically significant.

\section{Results}

DOG STUDY

The patterns of gastric emptying before and after

Table I Effect of carbachol on gastric emptying before and after vagotomy in the dog (mean $\pm S E$ of three experiments in each dog)

${ }^{1}$ Represents significant increases in the rate of gastric emptying in comparison with the saline control. 


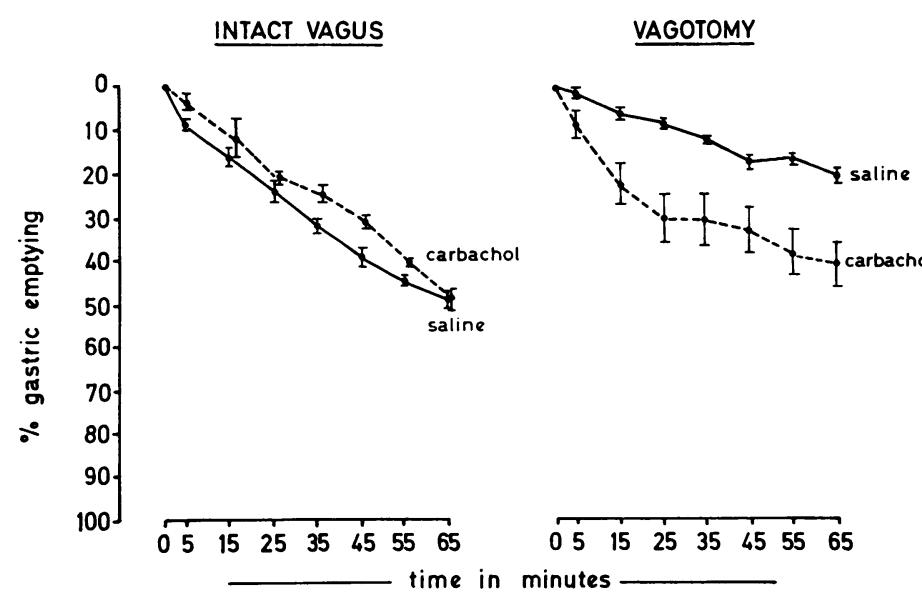

Fig. 2 The effect of subthreshold carbachol on the rate of gastric emptying in man. On the left are shown the results in five volunteers (controls) with intact vagi. On the right are shown the results in five patients after complete truncal vagotomy.

vagotomy with pyloroplasty are given in Fig. 1 and Table I.

\section{Before vagotomy}

The lowest three doses of carbachol $(0 \cdot 06,0 \cdot 125$, and $0.25 \mu \mathrm{g} / \mathrm{kg}$ ) did not affect the rate of gastric emptying in comparison with the rates observed after injection of saline. These doses were therefore subthreshold. Significant increases in the rate of gastric emptying occurred when the larger doses of carbachol were used.

\section{After vagotomy}

The three subthreshold doses of carbachol all increased the rate of gastric emptying significantly $(P<0.001)$ compared with the emptying rate in response to saline. The rates of emptying in response to all three doses of carbachol were similar to each other. Compared with the control rates before vagotomy, the rates in response to subthreshold carbachol after vagotomy were significantly faster $(P<0.003)$ at 10 minutes but not significantly different at the 20 - or 30 -minute measurements.

The rate of emptying in response to saline was significantly slower after vagetomy than before $(\mathrm{P}<0.05)$.

\section{HUMAN STUDY}

The patterns of gastric emptying before and after truncal vagotomy with pyloroplasty are given in Figure 2 and Table II.

\section{Before vagotomy}

The dose of carbachol used $(0.06 \mu \mathrm{g} / \mathrm{kg})$ did not increase the rate of gastric emptying observed when saline was given and was therefore subthreshold. In fact the rates measured at 35,45 , and 65 minutes after the injection of carbachol were slightly and significantly slower $(\mathrm{P}<0.025)$ than after the saline injection.

\section{After vagotomy}

In response to subthreshold carbachol there was a significant acceleration of gastric emptying when compared with the response to saline $(P<0.05)$. There were no significant differences between the rates in response to carbachol after vagotomy and those after saline in the control subjects with intact vagi.

As in the dogs, when saline was used the emptying rates after vagotomy were significantly slower $(P<0.05)$ than in the corresponding measurements in the subjects with intact vagi.

\section{Discussion}

In dog and in man the rate of gastric emptying was decreased soon after vagotomy and pyloroplasty. Whether the rate of emptying approaches normal values with the passage of time is controversial (Goodall, 1966; Griffith, Owen, and Shields, 1966; Buckler, 1967; George, Connell, and Kennedy, 1968).

Subthreshold carbachol significantly accelerated the slow rates of emptying after vagotomy

\begin{tabular}{|c|c|c|c|c|}
\hline \multirow{2}{*}{$\begin{array}{l}\text { Times of Measurements } \\
(\min )\end{array}$} & \multicolumn{2}{|c|}{ Vagus Intact (five volunteers) } & \multicolumn{2}{|c|}{ Vagotomy and Pyloroplasty (five patients) } \\
\hline & Saline & Carbachol & Saline $e^{1}$ & Carbachol $^{2}$ \\
\hline 5 & $8.2 \pm 1 \cdot 2$ & $3.6 \pm 1.8$ & $1.8 \pm 0.9$ & $8 \cdot 6 \pm 3 \cdot 1$ \\
\hline 15 & $16.1 \pm 2.7$ & $11 \cdot 5 \pm 4 \cdot 8$ & $6.6 \pm 1.3$ & $22 \cdot 3 \pm 5 \cdot 1$ \\
\hline 25 & $23.9 \pm 2.9$ & $20.8 \pm 0.98$ & $9.2 \pm 0.6$ & $30 \cdot 5 \pm 5.2$ \\
\hline 35 & $31.96 \pm 1.6$ & $24.2 \pm 1.6$ & $14.5 \pm 1.8$ & $30 \cdot 4 \pm 5.9$ \\
\hline 45 & $39.04 \pm 2.03$ & $30 \cdot 5 \pm 1 \cdot 2$ & $17.9 \pm 1.99$ & $33 \cdot 3 \pm 5 \cdot 7$ \\
\hline 55 & $44.8 \pm 1.4$ & $40.2 \pm 0.5$ & $16.6 \pm 1.5$ & $38 \cdot 4 \pm 5.9$ \\
\hline 65 & $49 \cdot 3 \pm 2.4$ & $49 \cdot 7 \pm 2 \cdot 3$ & $21.04 \pm 1 \cdot 5$ & $41 \cdot 1 \pm 4.9$ \\
\hline
\end{tabular}

Table II Effect of subthreshold carbachol on gastric emptying before and after vagotomy in man (percentage gastric emptying, mean $\pm S E$ )

${ }^{1}$ Significantly slower than emptying rates of patients with intact vagi.

${ }^{2}$ Significantly faster than control (saline) vagotomy results, but not significantly different from normal rates of emptying in subjects with intact vagi. 
and pyloroplasty in both dog and man. This result confirmed our original hypothesis that Cannon's law might apply to the parasympathetic nervous system. Further exploration of this phenomenon might throw some light on aberrations of motility after vagotomy.

The development of denervation supersensitivity depends on total denervation of an organ. In studies on monkeys, Binder, Bloom, Stern, Solitare, Thayer, Spiro, and Poindexter (1968) found supersensitivity of the oesophagus to a cholinergic drug, mecholyl, only after division of both vagal trunks. By inference, the development of 'denervation supersensitivity' of the stomach depends upon complete denervation of the stomach.

At present, the Hollander insulin test (1948) is used to assess the completeness of gastric vagotomy. This test involves nasogastric intubation and an injection of insulin, both of which are unpleasant to the patient. Furthermore, interpretation of the results is difficult and controversial (Bachrach, 1962; Bank, Marks, and Louw, 1967). There is a real need for a simpler test which would be at least equally informative. 'Denervation supersensitivity' might provide the basis for such a test. The basis of this method would be that subthreshold cholinergic stimula- tion would cause an increased rate of emptying of the completely denervated stomach but not of the partially denervated stomach.

\section{References}

Bachrach, W. H. (1962). Laboratory criteria for the completeness of vagotomy. Amer. J. dig. Dis., 7, 1071-1085.

Bank, S., Marks, I. N., and Louw, J. H. (1967). Histamine- and insulin-stimulated gastric acid secretion after selective and truncal vagotomy. Gut, 8, 36-41.

Binder, H. J., Bloom, D. L., Stern, H., Solitare, G. B., Thayer, W. R., Spiro, H. M., and Poindexter, E. R. (1968). The effect of cervical vagotomy on oesophageal function in the monkey. Surgery, 64, 1075-1083.

Buckler, K. G. (1967). Effects of gastric surgery upon gastric emptying in cases of peptic ulceration. Gut, 8, 137-147.

Cannon, W. B. (1939). A law of denervation. Amer. J. med. Sci., 198, 737-750.

George, J. D., Connell, A. M., and Kennedy, T. (1968). Gastric emptying in patients with post-vagotomy diarrhoea. (Abstr.) Gut, 9, 732.

Goodall, P. (1966). The effect of vagotomy and a drainage procedure on the rate of gastric emptying. (Abstr.) Brit. J. Surg., 53, 995.

Griffith, G. H., Owen, G. M., and Shields, R. (1966). The rate of gastric emptying in gastroduodenal disease. (Abstr.) Brit. J. Surg., 53, 995.

Hollander, F. (1948). Laboratory procedures in the study of vagotomy (with particular reference to the insulin test). Gastroenterology, 11, 419-425.

Johnson, H. D. (1969). Personal communication.

Jones, T., Clark, J. C., Kocak, N., Cox, A. G., and Glass, H. I. (1970). Measurement of gastric emptying using the scintillation camera and CS. Brit. J. Radio ${ }^{120}$ (to be published). 